\title{
Research on the Change Trend of Chinese Manufacturing Service Input Coefficient
}

\author{
Hui-ming ZHUANG \\ Fujian Commercial College, Fuzhou, Fujian, China \\ Jin-ran CHEN \\ School of Economics \& Management, Central China Normal University, Wuhan, Hubei, China
}

\begin{abstract}
This paper finds that China itself takes up a large part of the direct consumption of Chinese manufacturing industry, and there lacks demand for the inputs of service elements, and the servitization of manufacturing progresses slowly, and the inner structure is at low level, all of which lead to an unreasonable industrial interrelation status in which the push effect of China's manufacturing industry on national economy and the pull effect of China's national economy on manufacturing industry are both higher than that of manufacture-related service industry.
\end{abstract}

KEYWORD: Manufacturing; Service; Input and Output; Industry Interrelation

\section{INTRODUCTION}

Study of Chinese manufacturing industry and service industry especially the relationship between manufacture-related service industries and analysis of the present situation and the developing trend of Chinese manufacturing industry service, will help the transformation and upgrading of industrial structure of Chinese manufacturing industry, so as to get rid of situations in which China is always in the bottom of the "smiling curve" and realize a real sense of "World top" both from scale and quality.

\section{LITERATURE REVIEW}

For research in manufacturing services, foreign scholars have made some achievements, which can be roughly divided into two aspects: one is from the point of the interaction and integration of the manufacturing industry and service industries, analyzing the degree of interdependence between these two industries. For example, Marshall (1988) concluded that the proportion of manufacture-related service industry invested in manufacturing industry was significantly less than that of in service industry based on the input-output tables in 1968 and 1979. Besides, Park (1994) came to similar conclusions by analyzing the evolution trend of manufacturing and services industries based on the public input-output tables of countries in the Asia-Pacific region. Uno (1989) revealed that the Japanese manufacturing intermediate input has been evolving into a service-orientation in the framework of the interaction of manufacturing and services industries. The other one regards manufacturing service as the starting point, and the key point lies in the trends of the servitization of manufacturing. Pioneer representatives are Vandermerwe and Rada (1988), and they took the lead in studying and putting forward the trends of the servitization of manufacturing. Szalavetz (2003) made a complete, scientific definition of the servitization of manufacturing, and concluded that manufacturing enterprise transformed the manufacture-centered value chain into the service-centered one in order to obtain competitive advantage. Stille (2003) analyzed the correlation between German manufacturing activities and service activities, and found that many manufacturing enterprises are increasing the proportion of the service elements in day-to-day production. Pilat \& Wolfl's empirical evidence also proves that services play an important role in the process of manufacturing production. And domestic scholars also carried on the preliminary research and exploration of manufacturing services. Yue-jin guo (1999) analyzed the performance, causes, advantage of the servitization of manufacturing and provided some enlightenment for Chinese enterprises. Gao-ge Song (2005) examined the function and status of the servitization of products in the process of development of circular economy. Ji-guo liu and Yi-ting Zhao (2006) carried on an international comparison about the service trend of the manufacturing industry's intermediate input among the nine countries in the OECD. Li-fang Huang 
(2011) conducted a comprehensive analysis of industries fit between service industry and manufacturing industry from the angle of the former embedded in the latter one. Lin-yan sun (2011) has carried on a more comprehensive analysis of the transformation and upgrading of the service-oriented manufacturing industry. These research play a significantly guiding role in deepening understanding of the developing course of the servitization of Chinese manufacturing industry.

\section{INPUT-OUTPUT METHODS AND INDEX}

Direct consumption coefficients mean that in the process of production and operation activities, when a service department gains each additional unit output, the value of direct consumption of goods or services of other departments. Its computation formula is:

$$
a_{i j}=x_{i j} / X_{j} \quad(i, j=1,2,3 \cdots \cdot \mathrm{n})
$$

Among them, $a_{i j}$ denotes the direct consumption coefficient; ${ }^{x_{i j}}$ is the value of the goods or services of department $i$ 's production, which consumed directly by $j$ department in its course of production and business operation activities. ${ }_{j}$ stands for the total investment of $j$ department. By the definition we can see that the coefficient reflects the degree of the direct dependence on each of the two departments. It suggests the amount of the intermediate products which needs to be increased in the corresponding industry, when a department wants to achieve one unit growth.

\section{CHINA MANUFACTURING SERVICE INPUT VARIABLE ANALYSIS}

\subsection{Service investment of Chinese manufacturing industry increased yearly}

From Figure 1, since the year of 1997 to 2007, the service investment scale of Chinese manufacturing industry has been increasing rapidly. From $\$ 9.386$ trillion in 1997 to $\$ 37646.4$ quadrillion in 2007, with the decade there has increased by nearly 4 times, which was a good momentum in the process of the servitization of manufacturing in China and also fully shows the intermediate investment of Chinese manufacturing industry on service industry has been gradually expanding and the developmental structure of Chinese manufacturing industry is tending to improve.

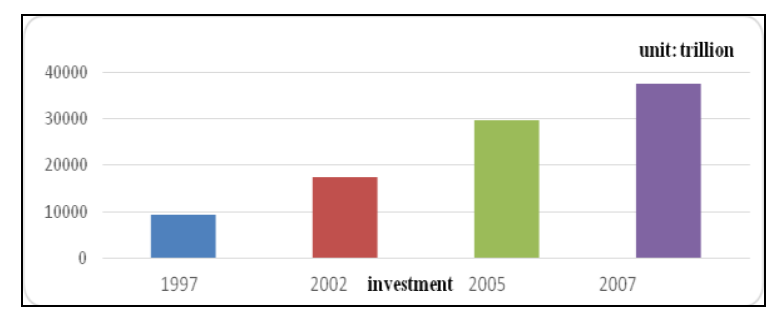

Fig 1. Service investment of China's manufacturing industry each year

The expansion of the scale of the service investment in the manufacturing industry lies in technological innovation and the deepening of the division of labor. First, as the further development of scientific and technological progress and industrial division of labor, the transaction mechanism is becoming increasingly complex and industrial chain is becoming more detailed, thus the segmentation way of the industrial value transformed from production sector-based to industry chain nodes-based. Therefore, enterprises gather its superior resource to focus on the core link in the industrial value chain to get their core competence. Meanwhile, it will outsource some auxiliary functions such as marketing, accounting, legal, logistics within the enterprise to some independent specialized enterprise in the market. Second, with the deepening of division of labor, the species of the products have been increasing as well as the differentiation, and the product life cycle has been shortened, and the market boundary has been expanded, and the way to organize production has become more and more complex, all of which will inevitably lead to the rapid growth of the demand for services of the manufacturing enterprise.

\subsection{The major direct consumption of Chinese manufacturing industry comes from itself}

Figure 2, Figure 3, Figure 4, Figure 5 respectively show the direct consumption coefficient of Chinese manufacturing industry on national economy sectors. First of all, through the comparison of data from 1997 to 2007, the major consumption of Chinese manufacturing industry comes from itself (the index of each year suggested more than 50\% degree of dependence on average). Among them, the top three are manufacturing industry, services industry, mining industry, and the construction industry was at the bottom of the direct consumption level. Further analysis shows that among the manufacturing industry, technology-intensive manufacturing industry shows the most dependence on manufacturing (the index is 0.4652 in 1997 and the highest 0.7016 in 2007); Followed by capital-intensive manufacturing ( the index is 0.5073 in 1997 and 0.4852 in $2002,0.5065$ in 2005 to 0.5607 in 2007, in a relatively stable growth); and 
the labor-intensive manufacturing shows lowest dependence on the manufacturing (increasing yearly from 0.3941 in 1997 to 0.4607 in 2007). (For better understanding, we use abbreviation. Agr stands for agriculture, Min stands for mining, Manu stands for manufacturing, Sup stands for supply, Con stands for construction and Ser stands for service. And the blue line represents Labor-intensive, the red line represents Capital-intensive, and the green line represents Technology-intensive.)

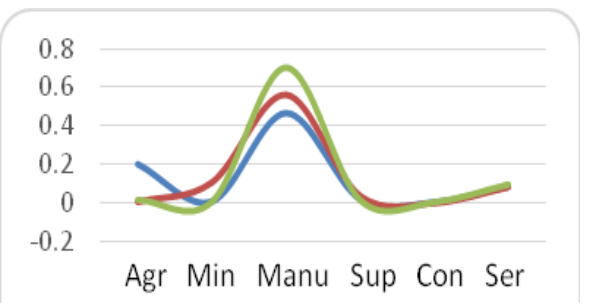

Fig 2. The direct consumption coefficients of national economic sectors in 2007

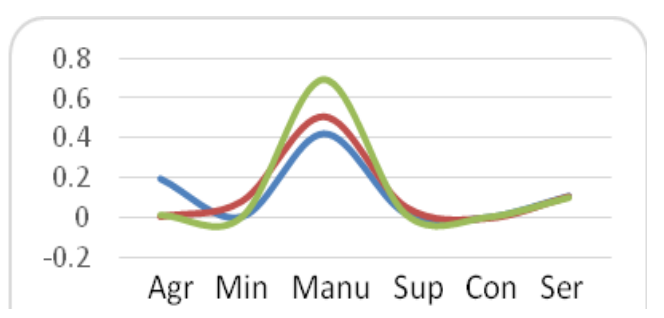

Fig 3. The direct consumption coefficients of national economic sectors in 2005

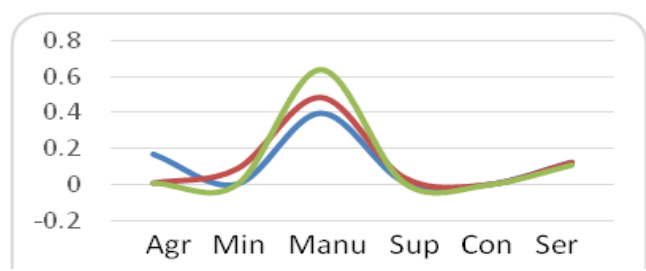

Fig 4. The direct consumption coefficients of national economic sectors in 2002

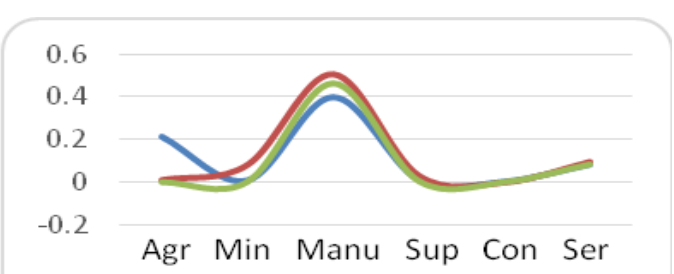

Fig 5. The direct consumption coefficients of national economic sectors in 1997

From the point of the intermediate investment demand, manufacturing industry shows a typical feature which is "high drawing, low value-added". More specific, the excessive dependence on manufacturing itself, especially in technology-intensive and capital-intensive manufacturing, and the increasing investment of physical capital, all of which restrict the manufacturing industry's sustainable development and its efficiency improvement. There is no doubt that the status quo of Chinese industrial relatedness is determined by the economic development stage and industrialization level. To maintain Chinese strong growth momentum, the inevitable choice in the process of developing countries' industrialization is to develop manufacturing industry and processing trade-based export-oriented strategy.

\subsection{The overall direct consumption level of the service industry is low}

Internal services within the manufacturing industry, such as enterprise technical quality, human resources quality, operation efficiency, asset number, which embedded in manufacturing industry through service industry, have become more and more important for manufacturing enterprise' competitiveness, surpassing the traditional determinants. These services include not only product and process development, design, logistics, expand training, pre-job training, and value chain management, but also organization development and coordination, human resources management, accounting, legal and financial services. From Figure 2 to Figure 5 we can find that Chinese service industry is embedded in the manufacturing industry, the overall level of manufacturing industry consumption of service industry is not high, the average consumption coefficient per year of the whole manufacturing industry on service industry are around $10 \%$, far below the industrial dependent degree of the manufacturing industry, which is $50 \%$. For more specific information of the fluctuation rules, the consumption coefficients of three manufacturing sectors in 1997 are 0.0815, 0.0971, 0.0884 , and in by 2002 , the index rise to 0.1254 , $0.1232,0.1104$, then in 2005 , it started to decline to $0.1069,0.1089,0.0998$ respectively, and in 2007, they are $0.0826,0.0832,0.0925$, which presents an inverted $\mathrm{u}$-shaped trend of change. Moreover, the overall coefficient didn't change much and it has remained stable at $8 \%$ to $10 \%$. This fully suggests that trends of the servitization of Chinese manufacturing are not evident, and the positive interaction between the two industries has not been formed. One of the reasons is that the industry characteristics, policy system, and the enterprises' awareness of manufacturing industry lead to the inefficiency of service products' supply. And the second reason is all about the export-oriented strategy. In one hand, the strategy failed to generate the effective demand for service industry; in other hand, it speeds up the vicious competition in the elements-acquiring area within the industry, which will greatly hinder the process of the servitization of manufacturing and restrict its rapid development. 


\subsection{Comparisons between China and other countries in manufacturing services investment}

In comparison of the direct consumption coefficient with the United States and Japan, the average intermediate investment rate of China is $10 \%$, which is far less the United States and Japan's 20\%, which suggests that service industry of our country contributes poorly to the manufacturing industry. In spite of the lower average level compared with the United States and Japan, China's manufacturing industry consumption comes largely from itself, while the consumption of service industry is not high. This totally suggests that the development of China's manufacturing industry is at the expense of high energy consumption, high material consumptions and high pollution. The embedding level of service industry in manufacturing industry is kind of low, and the interaction and integration of the two failed to be effectively mobilized, which strongly contrasts with American and Japanese highly developed service industry and highly industrial fit with manufacturing industry.

Table 2. The manufacturing services investment coefficient in United States, Japan and China

\begin{tabular}{|l|l|l|l|l|l|}
\hline Year & USA & Year & Japan & Year & China \\
\hline 1997 & 0.2123 & 1995 & 0.1895 & 1997 & 0.0906 \\
\hline 2002 & 0.2265 & 2000 & 0.1947 & 2002 & 0.1223 \\
\hline 2007 & 0.2003 & 2005 & 0.1949 & 2007 & 0.0835 \\
\hline
\end{tabular}

The reason are that at present, China is still in the middle stage of industrialization, along with the lagging progress of service industry, the raw production in manufacturing industry and unfavorable status in international industrial division of labor. These are manifested in the following aspects.

1. About the development of service industry, compared with the developed countries, China's service industry, especially the productive service industry, accounts for a rather low share in GDP, and the overall development level is not high, which makes it difficult to meet the demand for manufacture-related service industry from manufacturing industry and service industry production, and it hinders the manufacturing production investment structure's softening trend.

2. In terms of industrial structure, labor-intensive industries are still the leading mode in our country. Production activities are more concentrated in the link of processing and assembly manufacturing which is in the middle of the industrial chain. Investment in research and development, design, marketing is low, which is an important factor restricting the combined development of our country's manufacturing industry and service industry.
3. About the status in the international division of labor, developed countries take trans-corporation as carrier and make China's industrial system firmly locked in bottom level of the global industry value chain, through direct investment in specific industries and distortion of the trade patterns. Professional services necessary in the process of production for the foreign-funded enterprises are basically provided by the parent company. The product lines and industrial chain extension in the local market is short, and the demand for local design, technical services, marketing, finance and other demand is kind of low, which results in that the industrial relatedness between China's manufacturing industry and service industry, especially the manufacture-related service industry, is cut. In comparison, both the United States and Japan are in the post-industrial era, the service industry of which are developed, and production structure level is high, along with the dominant position in the international division of labor, all of which make the volume of service economy larger and the pull effect of the service industry on national economic sectors stronger.

\section{REFERENCE}

[1] Juleff - Tranter L E. The Advanced producer services - just a service to manufacturing. The service Industries Journal, 1996, (3).

[2] Paolo Guerrier i. Valentina Melician. I Technology and international competitiveness, the interdependence between manufacturing and producer services. J StructuralChange and Economic Dynamics, 2005, (16): 489-502.

[3] Huang Lifang. China's producer services embedded study on the relationship between the manufacturing, based on an empirical analysis of the input-output table. Journal of economic issues in China, 2011 (01).

[4] Shao Shuai. Manufacturing value-chain of input-output analysis, in guangdong, for example. Journal of industrial economy, 2012 (01).

[5] ZhuangHuiMing, an. The structure of China's service industry development, industry associations and motivation. Journal of international business, foreign economic and trade university, 2012 (8).

[6] ji-guo liu. Manufacturing industry development trend of service research. Beijing: economic science press, 2009 (05).

[7] Wei lei, Hou Ruirui. APS and manufacturing industry in the developed countries rely on the evolution of the characteristics and its enlightenment to China - based on input-output table of international comparative analysis. Journal of lingnan journal, 2011 (05).

[8] Joe all, kinghan letter, tao by the fai. Interactive development of producer services and manufacturing research - 1997-2007, an empirical analysis of the input-output tables of jiangsu province. Journal of nanjing social science, 2012 (03).

[9] ji-guo liu, Zhao Yiting. Manufacturing intermediate input trend analysis of service - based on nine countries in the OECD's macro empirical. Journal of economics and management, 2006. 